\title{
O INTELECTUAL EM QULSTÃO: a saga do padre Nando
}

Henrique Roriz Aarestrup Alves

Tivesse sido possível construir a Torre de Babel sem subir nela, e a sua construção teria sido consentida.

FRANZ KAFKA

No romance Quarup, de Antonio Callado, pode-se perceber uma forte preocupação referente à situação dos indígenas xinguanos e dos camponeses. As minorias indígenas encontram-se em processo progressivo de aculturação, pois foram contaminadas pela colonização ocidental durante séculos. Esses grupos encontram o apoio de intelectuais, como Fontoura e padre Fernando, para ter seu espaço territorial e cultural respeitados pela civilização brasileira. Outra minoria relevante é a camponesa, a qual manifesta sua voz de modo mais incisivo no romance, através da ação organizada politicamente pelas ligas. Novamente, intelectuais como Januário, Levindo e o próprio Nando fazem-se presentes, dirigindo e estabelecendo as estratégias dos camponeses para causar maior impacto perante os poderosos dirigentes e a sociedade brasileira em geral.

O personagem Nando, através de sua saga nesse processo, de seu contato com os índios do Xingu e demais personagens, como Fontoura e Ramiro, em suas andanças pelo Rio de Janeiro e Recife, onde se envolve com causas populares, vai tecendo uma rede de relaçôes sociais particular, vai formulando com esse material um "corpo identitário" próprio: 
- Que tal os famosos índios? - disse Otávio a Nando.

- Ah, você não sabe a importância que terão sempre para mim estes primeiros dias aqui no Xingu. Estou me sentindo feito um disco de cera numa gravação, sei lá.

- Guardando tudo nas ranhuras - disse Otávio. (Negrito meu). (CALLADO, 1984, p. 184).

Nessa passagem, pode-se perceber que padre Nando assume uma postura aberta para vivenciar suas experiências no Xingu, ou seja, suas antigas ideias e opiniôes sobre os indígenas estáo prontas para ser relativizadas e modificadas, de acordo com o que for aprendendo nesse contato com eles e com os outros personagens. Nando aprende inclusive a perceber e a aceitar o projeto de Fontoura, que é deixar os índios viverem em sua própria cultura sem grandes interferências da cultura branca, tentando minimizar ou retardar os efeitos da aculturaçáo. Nando aprende a respeitar essa postura de Fontoura, e, com o tempo, incorpora-a também em suas reflexóes e açóes que envolvem os indígenas. Assim, o personagem vai "guardando tudo nas ranhuras, como um disco de cera numa gravação”, ou seja, à identidade formada por vivências passadas somam-se outras vivências, muitas vezes gravadas por cima, como numa estrutura arquitetônica em palimpsesto, onde novas camadas se sobrepóem às antigas que continuam existindo, porém ficam escondidas ou guardadas sob as novas. É importante observar que essas noções de estruturas em palimpsesto, trazidas da arquitetura para ilustrar a construção de um conceito de identidade na literatura, não possuem a estaticidade e linearidade de uma estrutura especificamente arquitetural. A identidade em palimpsesto, no caso do personagem Nando, possuiria as divisóes entre as camadas não muito nítidas, não exatamente fixas, o que permitiria uma constante comunicação e influências entre elas. Através da própria dinâmica da memória, as camadas antigas deixariam suas marcas ou vestígios nas camadas mais recentes. Mas, apesar desse constante contato entre essas camadas que formam uma identidade dinâmica e em permanente mutação e construção, é possível identificar essas estruturas através do percurso que o personagem realiza no romance. Nando inicia sua saga como um sacerdote realmente comprometido com as normas e as atividades da instituição católica a que pertence. Mais tarde rompe com o celibato, desvincula-se da Igreja e torna-se revolucionário, envolvendo-se com as questôes populares, além de trabalhar como funcionário público do SPI (Serviço de Proteção aos Índios). Aprende técnicas de amar, de forma a proporcionar prazer à parceira, e as ensina a seus discípulos, mais ao final do romance. Em cada fase do processo de construção identitária de Nando pode-se perceber alguns resquícios das fases anteriores. Como amante de mulheres feias, e mestre na arte de amar, Nando parece exercer um 
outro tipo de sacerdócio, onde os discípulos sorvem avidamente seus conhecimentos, e a atenção aos mais desfavorecidos ainda é prioridade. Pode-se perceber que por debaixo da camada do homem que se envolve com desfavorecidos está a do padre, do sacerdote comprometido com a caridade e o bem-estar dos seres humanos de uma forma geral, ou seja, é possível detectar os vestígios e a presença de uma camada anterior, visível em alguns pontos onde a camada mais recente torna-se mais tênue, ou talvez translúcida o suficiente para que seja possível vislumbrar um vulto com uma batina negra por trás do revolucionário barbado, vestido como um homem comum, e "amante de mulheres feias"em plena atividade ao exercer esse novo sacerdócio.

Cada passo que Nando ensaia no romance é acompanhado da lembrança de como se constituía sua identidade anterior, de suas antigas ideias e apreensóes do meio circundante em que vivia, seja como padre, como "ex-sacerdote" e funcionário do SPI logo em seguida, seja como revolucionário e apaixonado por Francisca. As fases anteriores ficam registradas na memória, em camadas que vão se acumulando, mas frequentemente se comunicando com dinamicidade e sem muita linearidade nesse processo, de acordo com os acontecimentos que o personagem vivencia e com a passagem do tempo no romance:

Ao lado dessas metáforas visuais, outra constante são as metáforas arqueológicas que sugerem a escavação dos significados, para recuperar as ruínas da memória. Tais imagens ligam-se a outra imagem correlata - a do palimpsesto. Lê-se a cidade como um composto de camadas sucessivas de construçóes e "escritas", onde estratos prévios de codificação cultural se acham "escondidos" na superfície, e cada um espera ser "descoberto e lido”. (Negrito meu). (GOMES, 1994, p. 78).

Segundo Renato Cordeiro Gomes, em sua obra Todas as cidades, a cidade: literatura e experiência urbana (1994), uma cidade pode ser lida de acordo com as sucessivas camadas de construçôes culturais e escritas que vão se acumulando em sua memória, ou na superfície disponível à visão ou ao alcance dos instrumentos capazes de realizar esses trabalhos arqueológicos de leituras. Um processo alusivo a esse referido pelo autor parece ocorrer com o personagem Nando, na medida em que a superfície disponível de sua memória, elemento fundamental de sua construção identitária, também guarda níveis estruturais palimpsestos de identidade. Quando "escava” sua memória, Nando lembrase, por exemplo, de seu companheiro de sacerdócio, padre Hosana, do sentimento de revolta e do comportamento libertino desse personagem, da arma que guardava para assassinar D. Anselmo, símbolo das normas e regras da Igreja. A postura de Nando era a de alguém distante dessas preocupaçóes, mas, à medida que se depara com suas questóes 
éticas sobre sexo, ele passa a vivenciar conflitos; resolve-os modificando-se, deixando oficialmente de ser padre, rompendo com o celibato, alterando suas convicçôes e mostrando-se aberto e receptivo a essas novas "pinceladas" e camadas de "tinta fresca" que se sobrepóem às velhas, compondo um novo quadro identitário que vai surgindo, mas que exibe, em suas ranhuras e em pontos mais sutis, a coloração de pinceladas mais antigas e a silhueta de formas anteriores. Mesmo após concluir as construçóes posteriores, Nando consegue identificar e localizar "arqueologicamente" as estruturas anteriores que compunham sua identidade em sua memória, ou seja, lembra-se do padre que era, cheio de dogmas e preconceitos etnocêntricos com relação aos indígenas, e passa a se constituir como "ex-sacerdote", ou como um novo sacerdote, o qual se desenvolve e se descobre na arte de amar, defendendo a cultura indígena e os desfavorecidos nas cidades do Rio de Janeiro e Recife.

Quando Nando entra em contato com a vida urbana do Rio de Janeiro pela primeira vez, presencia, em companhia das pessoas ligadas ao SPI, sessóes de cheirar éter e beber uísque, a discordância de ideias entre Ramiro e Fontoura, além do descaso das instituiçôes públicas com o bem-estar dos índios e dos cidadãos brasileiros em geral. Esse descaso é retratado na própria figura de Ramiro, um chefe do SPI mais interessado na França, em drogas euforizantes e em Sônia que nas questôes propriamente indígenas. Nesse ambiente, as dores causadas pelas dificuldades de se viver no caos urbano, com todos os obstáculos e contradiçóes, conflitos e ideias discrepantes envolvidos nesse processo, são amenizadas nas sessóes de cheirar éter. Mas, além das ditas qualidades proporcionadoras de prazer do lança-perfume, pode-se perceber uma outra função embutida nesse processo. Segundo o personagem Falua, jornalista da Folha da Guanabara, o éter possuiria uma função "educativa", capaz de proporcionar descobertas a respeito da própria identidade, na medida em que o usuário mergulha em si mesmo e entra em contato com camadas mais profundas do seu próprio eu. $\mathrm{O}$ personagem defende o uso do éter em escolas, e considera o carnaval como um fenômeno popular em que o inconsciente do povo fica escancarado coletivamente, o que seria enriquecedor e promoveria seu autoconhecimento:

- [...] O que eu quero dizer é que povo nenhum antes de nós tornou o porre de éter um festim popular. $\mathrm{O}$ carnaval é isso, é um povo inteiro de inconsciente escancarado durante três dias e quatro noites.

— [...] Nós devíamos usar o éter nos colégios — disse o Falua - para ensinar aritmética às criancinhas adormecidas. Devíamos fazer um oleoduto de éter pelo Corcovado acima, que fosse dar numa bisnaga na mão do Cristo que esparziria permanentemente 
o frio e delicioso conhece-te-a-ti-mesmo sobre os cariocas, o povo mais genial desde os atenienses. (Negritos meus). (CALLADO, 1984, p. 123)

Segundo Falua, criancinhas despertariam de uma sorumbática realidade escolar para uma outra "dimensão", em que seria mais aguçada e sensível a percepção. O lança -perfume proporcionaria também uma experiência mítico-religiosa para o personagem, pois até a imagem do Cristo Redentor carioca é usada em sua apologia ao éter, como se esse produto químico adquirisse poderes capazes de levar seus usuários à redenção da ignorância e da dor vivenciada na realidade efetiva. Náo alheio a esse processo encontrase Nando, que reage instantaneamente às ideias de Falua:

Nando apenas sorria, mais discreto que os outros, mas sentia um estranho desejo de éter. Ainda bem que não havia lança-perfume ali! Tinha saudade até do cheiro, tão repelente logo de ínicio, do dzim-dzim-dzim que precedia as visóes coloridas. (CALLADO, 1984, p 123-4).

Talvez o autor implícito esteja dando indícios de que Nando concorda com essa teoria, e que usará conscientemente o éter para contactar sua memória e suas camadas psicológicas mais profundas, constituintes da estrutura dinâmica de sua identidade. Realmente, isto vem a se confirmar quando Nando reconhece qualidades inclusive religiosas no éter, pois descobre a dimensão de sua paixão por Francisca, que passa a ser considerada como uma importante referência na descoberta da essência do personagem, de seu próprio "centro identitário". Nando reconhece a influência de Deus nesse processo:

- Não. Para dizer a verdade foi uma noite, depois do jantar, na casa de Ramiro, no Rio. Todos cheiravam lança-perfume. Eu criei respeito pelo éter, palavra. Eu acredito, com meu Falua, que as drogas em breve estarão no programa primário e ginasial. Onde ainda houver no currículo o ensino religioso elas serão indispensáveis.

[...] - Da ave-maria ao Apocalipse, tudo ficará mais claro com éter.

[...] - O sacerdote encontrou no lança-perfume a confirmaçáo da vontade de Deus — disse Nando - A qual era que eu amasse você.

[...] — Não adianta troçar de mim — disse Nando. — Estou falando a verdade e só a verdade. $\mathbf{O}$ éter me levou ao meu eu real e a busca desse eu real era você. (Negritos meus) (CALLADO, 1984, p. 331-2).

Nota-se, nessas passagens, que através das frestas do novo Nando que se apresenta após desvincular-se oficialmente da vida clerical, fervoroso amante de Francisca e simpatizante do uso do éter, é possível ainda perceber os resquícios do padre em sua iden- 
tidade, o qual se situa em "camadas" anteriores, acena pelas brechas das experiências posteriores que ajudam a constituir as novas "camadas", realizando esse singular processo de formação de um dinâmico palimpsesto, cujas fronteiras são tênues e não fixas.

Para ilustrar uma vez mais esse processo, a passagem abaixo mostra Nando passando por novas experiências, procurando vivenciar intensamente esses momentos de aprendizado:

Ao umedecer de novo o lenço, para não interromper o bem-estar e a sensação de poder, Nando lançou um olhar aos companheiros e viu que todos ressonavam, Ramiro no sofá, lenço chapado na cara como um alegre morto, Vanda, Falua e Sônia, cada um numa poltrona, lenço no colo e bisnaga abandonada no assento. Antes de aspirar o lenço gelado Nando viu, na mesa do único abajur aceso do seu lado, a bisnaga de vidro brilhando com um esplendor de diamante, palpitando como o revólver de Hosana. Entendia tudo e tinha nas mãos vida e morte. Não ia perder tempo fixando naquele instante ciência tão inesquecível. Cheirou guloso a plenos pulmóes a friagem perfumosa. Dzim-dzim-dzim nos ouvidos. Altos muros ruíram em silêncio e cores fulguraram em negrume de azul e pasta de escarlate. Aprendiz no estúdio de um pintor antigo, Nando tinha caracóis escuros que lhe caíam sobre a testa, borzeguins vermelhos de ponta revirada, pincel na mão e um sorriso de mofa nos lábios infantis. (CALLADO,1984, p. 93).

Nessa passagem, Nando procura extrair ao máximo alguma essência de si mesmo durante o uso do éter. No quadro em que pinta e age sobre sua identidade, "altos muros ruíram em silêncio", como brechas que se abrem nas fronteiras entre uma "camada" e outra, exibindo imagens pictóricas escondidas nas "camadas" mais profundas. Através dessa experiência, o personagem entra em contato com imagens coloridas e alucinantes, como se observasse um quadro onde dentro dele se via pintando outro quadro, caracterizando um processo de "mise-en-abîme". A imagem produzida por esse processo parece possuir algumas semelhanças com a estrutura em palimpsesto de identidade, pois ambas são organizadas em camadas que se aprofundam e se acumulam, ao mesmo tempo em que se comunicam. A diferença é que as camadas do palimpsesto só são visíveis quando, escavadas, uma fronteira se abre e exibe a(s) camada(s) anteriores. Mas mesmo assim as duas estruturas parecem dialogar, pois ambas ilustram um processo de mergulho nas profundezas do próprio eu realizado pelo personagem nessa passagem do texto. Em suas antigas imagens juvenis detectam-se as formas de "caracóis escuros que lhe caíam sobre a testa, segurando um pincel na mão e um sorriso de mofa nos lábios infantis". Essas experiências com o éter, portanto, Nando a vislumbrar seu quadro identitário, que se constrói pictoricamente no âmbito 
de uma "escavação arqueológica" realizada na memória, essa guardiã e instrumento essencial para a construção de uma identidade.

Nando transita com frequência entre a cidade do Rio de Janeiro e a reserva indígena Capitão Vasconcelos, no Alto Xingu, como se tentasse unir as duas dimensôes espaciais através da diminuição das injustiças sociais tanto na selva como na cidade. Ao trabalhar para o SPI no Xingu, defendendo os índios tanto de violências físicas como culturais, e ao participar de movimentos populares de trabalhadores rurais, buscando uma distribuição mais justa de terra e riquezas, ele idealiza uma nação. Nessa nação utópica, as discrepâncias entre o campo, representado pelo Xingu, e a cidade, representada pelo Rio de Janeiro, seriam minimizadas a ponto de unir-se em um conjunto mais harmônico e menos conflituoso, onde dificuldades pudessem ser superadas. Dentro desse conjunto de dificuldades situam-se lutas de classes, confrontos entre latifundiários e trabalhadores rurais, fazendeiros, grileiros e indígenas em suas reservas desrespeitadas, políticos inescrupulosos e cidadãos a mercê de seus desmandos. Ao mesmo tempo em que Nando vai se descobrindo e se construindo, constrói também uma utopia na qual vislumbra uma nação com todas essas questóes resolvidas. E, para chegar perto dessa imagem de nação brasileira, para tentar alcançá-la, o personagem se envolve tanto com as questôes populares no Rio de Janeiro e Recife quanto com as questôes indígenas no Xingu, situando essas atividades em um mesmo patamar de importância. Nando vai construindo-se como um verdadeiro revolucionário, pois alimenta a esperança de conseguir alterar a ordem social e influenciar no estabelecimento de um novo status quo, onde as questôes socioeconômicas já citadas seriam resolvidas. Mas o personagem esbarra em sua própria condição humana e na de outros personagens para realizar tal empreendimento, cujos alicerces requerem uma força sobre-humana ou praticamente divina para ser erguidos. Renato Cordeiro Gomes, ao citar "O emblema da cidade", de Kafka, ressalta a situação problemática daqueles que pretendiam construir a Torre de Babel, pois os desentendimentos e conflitos seriam detectados já no próprio processo de construção da torre, e não no castigo divino posterior:

No contexto kafkaniano, o desentendimento e os conflitos não são consequência da destruição, do ato do Pai, a figura que pune, porém do processo mesmo de construção (a luta de classes, os privilégios, a disputa do poder), do "mundo administrado". A torre e a cidade são um fazer permanente, sem fim, sempre incompleto, adiando o que estava por vir: o adiamento - tema recorrente em Kafka — do término da Torre pode significar o protelamento do seu arrasamento, que está prenunciado no emblema. (GOMES, 1994, p. 87). 
Assim, os conflitos sociais em que se envolve Nando seriam um indício de que na construção de sua utopia, ilustrada pela própria imagem mítica da Torre de Babel, já estaria o germe de sua impossibilidade. $\mathrm{O}$ personagem náo consegue realmente efetivar seus projetos ao final do romance, apesar do tom esperançoso contido nesse epílogo, onde as lutas ainda poderão continuar, e quem sabe a utopia poderá ainda se concretizar. Talvez a destruição efetiva da torre se confirme no texto de $A$ Expedição Montaigne, se for possível tomar a perspectiva extradiegética do autor empírico Antonio Callado, pois nesse romance a utopia de uma nação nos moldes pretendidos por Nando é totalmente descartada. Portanto, como uma autêntica utopia que não se realiza, a imagem de nação que Nando idealiza permanece no âmbito do desejo, pois como ilustra Renato Cordeiro Gomes, ainda referindo-se ao texto de Kafka, "a insensatez só seria revertida quando a Torre pudesse ser erguida com as marcas da harmonia e da Paz universal, no não tempo de um náo lugar da utopia, da transparência absoluta do sentido que anularia o absurdo" (GOMES, 1994, p. 87). Assim, talvez fosse possível a realização da utopia de Nando caso sua construção não fosse recheada de lutas e conflitos, e sim baseada na harmonia e na Paz universal. A sociedade brasileira idealizada pelo personagem seria semelhante a uma civilização situada nas alturas “celestiais” próximas do ente Supremo, onde as injustiças sociais e econômicas seriam banidas de uma vez por todas. Porém, essa instância utópica mostra-se inalcançável para o ex-sacerdote: rui sua "torre" rui das intempéries que surgem nas urbes brasileiras.

Nando se envolve com a Marcha das Ligas Camponesas na cidade do Recife quando volta de sua expedição ao interior do Brasil. Essa manifestação popular de insatisfação com os usineiros, políticos e demais poderosos termina com a prisão de Januário, Nando, Manuel Tropeiro e outros líderes. Esse conflito ilustra o esforço de Nando para implantar o "mundo de Levindo" na dura realidade circundante e resistente às tentativas de subversão do status quo. As lutas e a violência marcam também sua vida no cárcere como preso político, e na cidade de Recife durante o jantar em homenagem à memória de Levindo. Todas essas intempéries na vida do personagem, ocorridas nas duas urbes brasileiras, o Rio de Janeiro e o Recife, denunciam a impossibilidade de se erguer uma construção que elevará seus companheiros e os desfavorecidos em geral a um espaço, quase mítico, de liberdade e justiça social. Se, por um lado, a cidade é o espaço da esperança e de realização dos desejos onde a utopia pode se efetivar, por outro, pode ser o espaço dos conflitos, da desilusão, da exclusão e do sofrimento. Sandra Jatahy Pesavento, em O imaginário da cidade: visóes literárias do urbano (1999), afirma:

[...] uma metrópole propicia aos seus habitantes representaçóes contraditórias do espaço e das socialidades que aí têm lugar. Ela é, por um lado, luz, sedução, meca da cultura, 
civilização, sinônimo de progresso. Mas, por outro lado, ela pode ser representada como ameaçadora, centro de perdição, império do crime e da barbárie, mostrando uma faceta de insegurança e medo para quem nela habita. São, sem dúvida, visóes contraditórias, de atração e repúdio, de sedução e rechaço, que, paradoxalmente, podem conviver no mesmo portador. (PESAVENTO, 1999, p. 19).

Nando, ao mesmo tempo em que vislumbra sua civilização idealizada no espaço da urbe, presencia o caos e a confusão toda vez que se aproxima dela. A esperança e desejos embutidos nos atos revolucionários de Nando convivem com o repúdio e o sofrimento promovidos pelas injustiças sociais e a opressão. "A cidade torna-se um espaço dúbio de atração e repúdio, de sedução e rechaço" Atração e sedução porque o personagem sente a possibilidade de ver no espaço da urbe a instalação de sua utopia; repúdio e rechaço porque esse espaço contém, na realidade efetiva, características que o identificam com o caos e a barbárie promotores de medo, insegurança e sofrimento. Mas esse processo de construçáo de imagens da própria cidade contribui para que Nando construa sua própria identidade, pois "as representaçóes da cidade, construídas por cada um desses leitores, é que estabelecerão distâncias e aproximaçôes, perguntas e respostas umas às outras, como num jogo de espelhos" (PESAVENTO, 1999, p. 18). Ao entrar em contato com as diversas imagens da cidade, Nando elabora questôes e estabelece relaçóes entre elas, distâncias e aproximaçóes, perguntas e respostas umas às outras, realizando assim um processo que influencia em sua (auto)construção identitária.

No percurso de Nando pode-se perceber uma constante variação entre campo e cidade, entre o Xingu e Recife e Rio de Janeiro. Nando sai do mosteiro para o Rio, e ali ocorre uma significativa mudança em sua vida: entra em contato com os membros do SPI e com o éter. Do Rio parte para o Xingu, convive com os índios e seus problemas. Outro marco ocorre na vida do padre, que volta, mais tarde, ao Rio para deixar o sacerdócio e tornar-se funcionário do SPI. Mais uma vez retorna ao Xingu para realizar a expedição ao centro geográfico do Brasil, e descobrir o centro de si próprio contido na arte de amar Francisca. Em seguida, viaja para o Nordeste, onde se envolve com as atividades das Ligas Camponesas, em Recife. Retorna ao Rio de Janeiro, para tornar-se amante de mulheres feias e solitárias e ensinar a arte de amar aos jangadeiros e demais desfavorecidos. Finalmente, parte para o sertão de Goiás com Manuel Tropeiro para fugir das perseguiçóes políticas e unir-se aos movimentos revolucionários. Essa variação Xingu - Rio de Janeiro - Recife - Sertão de Goiás na trajetória de Nando ilustra sua tentativa de unir essas diferentes instâncias espaciais em um só conjunto. As realidades desses espaços possuem traços em comum, como o descaso das autoridades com a situação dos desfavorecidos e minorias brasileiras. Os índios xinguanos, os camponeses, 
os jangadeiros e prostitutas com quem convive o personagem formam um conjunto de desfavorecidos brasileiros, minorias que unem campo e cidade em um só projeto de civilização, no qual se imbricam imagens de esperança e descaso, utopia e sofrimento, contrastes e conflitos em espaços diferentes, mas formam uma estrutura única com dimensóes de nação. A região do Xingu, assim como engenhos, fazendas e outras áreas rurais, caracteriza-se pela prevalência da natureza circundante. A cidade, representada na obra pelo Rio de Janeiro e Recife, caracteriza-se pelas construçóes humanas, na tentativa de imitar a criação da natureza em forma de concreto e asfalto. Esta "selva de pedra" une a natureza original à natureza humana, na forma de urbe, com sua lógica, leis e cultura. A edificação da cidade, com suas constantes mudanças e (re)construçôes, assume um caráter de criação, aproximando os homens de Deus, cujas criaçôes envolvem a natureza e o próprio homem. Mas, como condenação divina,

a cidade está destinada a ser centro de conflito. O pecado inscrito, que acarreta o castigo, é aquele que se faz presente no próprio ato fundador. Se, como diz o texto sagrado, Deus fez o homem à sua imagem e semelhança e o fez de barro, é com o mesmo material que os homens constroem a cidade, igualando-se, com isso, a Deus, em sua obra, e buscando - pela verticalidade da construção — chegar aos céus, elevar-se até seus domínios. (PESAVENTO, 1999, p. 8).

Nando não consegue erguer a torre em direção à sua utopia, pois ela é destruída no próprio ato de construção, seja na Marcha das Ligas em direção ao Palácio do Governo, seja no jantar em memória de Levindo. Mas é através dessas próprias representaçôes simbólicas elaboradas nesse processo de construção/destruição de suas utopias e idealizaçôes que o personagem edifica, enfim, sua identidade, a qual, como um palimpsesto, com estruturas sobrepostas semelhantes às da Torre de Babel, não o leva à tão desejada civilização divina - mas, pelo menos, proporciona uma viagem ao centro de si mesmo e à autodescoberta.

\section{$\operatorname{soc} 2$}

\section{REFEREANCIAS}

ALMEIDA, Onésimo Teotônio. Em busca do conceito de identidade cultural: O caso açoriano como cobaia. Actas do Congresso do I Centenário da Autonomia dos Açores. Lisboa: Letras \& Letras, 1997. ANDERSON, Benedict. Nação e consciência nacional. Trad. Lólio Lourenço de Oliveira. São Paulo: Ática, 1989. 
BOBBIO, Norberto. Os intelectuais e o poder. Trad. Marco Aurélio Nogueira. São Paulo: Ed. da UNESP, 1997.

CALLADO, Antonio. Quarup. 12. ed. Rio de Janeiro: Nova Fronteira, 1984.

CÉSAR, José Vicente. Catequese e conversão dos indios do Brasil. Brasília: Antropos do Brasil, 1975.

ECO, Umberto. Seis passeios pelos bosques da fição. Trad. Hildegard Feist. São Paulo: Companhia das Letras, 1999.

GOMES, Renato Cordeiro. Todas as cidades, a cidade: literatura e experiência urbana. Rio de Janeiro: Rocco, 1994.

GRAMSCI, Antonio. Os intelectuais e a organização da cultura. 4. ed. Trad. Carlos Nelson Coutinho. Rio de Janeiro: Civilizaçăo Brasileira, 1982.

JUNQUEIRA, Carmen. Antropologia indígena: uma introdução à história dos povos indígenas no Brasil. São Paulo: EDUC, 1991.

PESAVENTO, Sandra Jatahy. O imaginário da cidade: visóes literárias do urbano. Porto Alegre: Editora da UniversidadelUFRGS, 1999.

RIBEIRO, Berta. Diário do Xingu. Rio de Janeiro: Paz e Terra, 1979.

RIBEIRO, Darcy. Os indios e a civilizaçâo: a integração das populaçôes indígenas no Brasil moderno. 2. ed. Petrópolis: Editora Vozes, 1977.

SAID, Edward W. Representations of the intelectual. London: Vintage, 1994.

SARTRE, Jean-Paul. Em defesa dos intelectuais. Trad. Sérgio Goes de Paula. São Paulo: Ática, 1994.

SÜSSEKIND, Flora. O Brasil não é longe daqui: o narrador, a viagem. São Paulo: Companhia das Letras, 1990.

\section{Resumo}

O romance Quarup, de Antonio Callado, apresenta vários personagens considerados como intelectuais. Entre eles está Nando, que constrói permanentemente sua identidade em contato com os outros intelectuais e as minorias brasileiras. Inspirado principalmente por Francisca e Levindo, Nando idealiza uma nação ao se envolver com as questōes dos indígenas xinguanos e dos camponeses. Mas sua utopia entra em conflito com a realidade efetiva do país, e ele sofre, inevitavelmente, as consequências da repressão e da violência dos poderosos. Apesar das terríveis dificuldades que o personagem encontra, o romance termina com um tom esperançoso em relaçáo às lutas revolucionárias ao lado da minoria camponesa.

Palavras-chave: Antonio Callado; Quarup; intelectual; identidade.

\section{Abstract}

In Quarup, by Antonio Callado, there are many characters considered to be intellectuals. Among them there is Nando who through out the contact with the intellectuals and the Brazilian minority is in an identity-building constant process. Inspired mainly by Francisca and Levindo, Nando idealizes a nation when he gets involved in the questions of the Xinguano Indians and the peasants. But his utopia clashes with the effective reality of the country and inevitably suffers the consequences of the repression and the violence of the mighty ones. In spite of the terrible 
difficulties faced by the character, the novel ends with a hopeful tone in relation to the revolutionary fights at the side of the peasant minority.

Keywords: Antonio Callado; Quarup; intellectual; identity.

Légua \& meia

Henrique Roriz Aarestrup Alves tem Mestrado e Doutorado em Literaturas de Língua Portuguesa pela PUC Minas. É Professor de Literatura Portuguesa, Literatura Brasileira e Teoria Literária da Universidade do Estado de Mato Grosso. 